\title{
Is There Enough Evidence to Prove That Hemodiafiltration Is Superior?
}

\section{Hideki Kawanishi}

Tsuchiya General Hospital, Hiroshima, Japan

\section{Keywords}

Online hemodiafiltration - Dialysis restated hypotension

Survival · Clinical study

\section{Abstract}

The evidence concerning online hemodiafiltration (HDF) includes the following: (1) the increase of removal of uremic toxin, (2) the prevention of dialysis rerated hypotension, (3) the recovery of survival, and (4) the recovery of dialysis related uncertain symptoms. Although clinical evidence has been noted, the hypothesis of the efficacy of HDF are still indefinite and require further precise research.

(c) 2018 S. Karger AG, Basel

\section{Introduction}

Many randomized controlled trials (RCTs) and observational studies of online hemodiafiltration (HDF) have been conducted, mainly in Europe. Clinical effects of in- creased removal of uremic toxin (including secondary effects due to dialysis fluid quality), prevention of dialysisrelated hypotension, improved survival, and improved dialysis-related symptoms have been reported. However, regarding the prevention of dialysis hypotension and improvement of survival effects, the mechanisms are still not clear. Furthermore, there are doubts about the effects of HDF.

\section{Prevention Mechanisms of Dialysis-Related Hypotension}

One clinical effect of HDF is the prevention of dialysisrelated hypotension. However, the volume of dialysate during HDF is larger than the amount of substitution fluid; therefore, the stabilization mechanism of circulatory dynamics observed in hemofiltration cannot be applied. This has been studied since the introduction of HDF. A recent study [1] reported that dialysis-related hypotension could be reduced with pre-online HDF as well as pre-

\section{KARGER}

(c) 2018 S. Karger AG, Basel

E-Mail karger@karger.com

www.karger.com/bpu
Hideki Kawanishi, MD

Tsuchiya General Hospital

3-30 Nakajima-cho, Naka-ku

Hiroshima 730-8655 (Japan)

E-Mail h-kawanishi@ tsuchiya-hp.jp 
Fig. 1. Gibbs-Donnan effect for dialysis-related hypotension prevention. Gibbs-Donnan effect: the electrolyte reaches equilibrium by diffusion through the dialysis membrane; however, with a non-diffusible anion (such as albumin), there are increases on the blood side of the membrane, the ion equilibrium collapses, and the diffusibility of $\mathrm{Na}^{+}$as a cation. $\mathrm{CV}$, convection volume; WR, water removal by ultrafiltration. Alb, albumin.

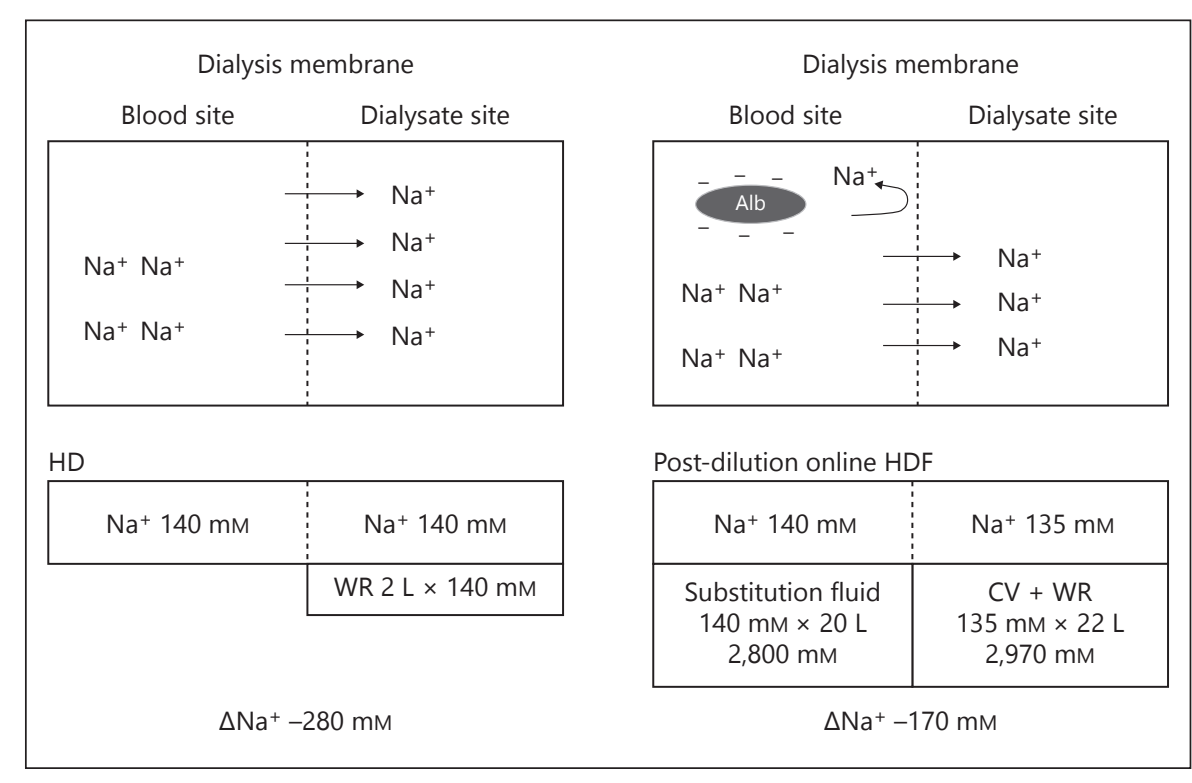

hemofiltration. Another study [2] indicated that this effect occurred with post-online HDF. RCTs and metaanalyses have proved the prevention of dialysis-related hypotension; however, the mechanisms are not clear.

\section{Gibbs-Donnan Effect}

Recently, the effects of dialysis hypotension prevention have been explained by $\mathrm{Na}^{+}$distribution. In general, the electrolyte reaches equilibrium by diffusion through the dialysis membrane; however, with a non-diffusible anion (such as albumin), there are increases on the blood side of the membrane, the ion equilibrium collapses, and the diffusibility of $\mathrm{Na}^{+}$as a cation decreases. As a result, bias regarding $\mathrm{Na}^{+}$distribution occurs between the dialysis membranes. This phenomenon is called the GibbsDonnan effect.

During HDF, a large amount of ultrafiltration occurs through the dialysis membrane, the albumin concentration increases on the blood side of the membrane, and the movement of $\mathrm{Na}^{+}$toward the dialysate side decreases, thereby reducing $\mathrm{Na}^{+}$removal (as compared with $\mathrm{HD}$ ) and maintaining blood pressure.

Figure 1 shows the $\mathrm{Na}^{+}$balance with online HDF. During ordinary hemodialysis (HD), assuming there is no Gibbs-Donnan effect, $\mathrm{Na}^{+}$is the same in the plasma and dialysate; with $\mathrm{Na}^{+} 140 \mathrm{mM}(\mathrm{mEq})$, the balance is -280 $\mathrm{mM}$ with $2 \mathrm{~L}$ of water removal. $\mathrm{Na}^{+}$from the substitution fluid enters the body in a volume of $2,800 \mathrm{mM}$ during post-HDF with a convection volume of $20 \mathrm{~L}$. However, the albumin concentration on the blood side of the membrane increases due to hemoconcentration. $\mathrm{Na}^{+}$concen- tration in the ultrafiltrate decreases to $135 \mathrm{~mm}$ due to the Gibbs-Donnan effect, the total $\mathrm{Na}^{+}$removal with the removal of $2 \mathrm{~L}$ of water was $2,970 \mathrm{mM}$, and the $\mathrm{Na}^{+}$equilibrium was $-170 \mathrm{mM}$. As a result, the $\mathrm{Na}$ load in the body increases compared with that during $\mathrm{HD}$, and blood pressure reduction can be prevented.

Because the albumin concentration on the blood side decreased with dilution, it was thought that the GibbsDonnan effect was less likely to occur with pre-HDF than with post-HDF. However, on the inner surface of the dialysis membrane, there was an increase in albumin concentration and the Gibbs-Donnan effect was exerted. In that case, the negative $\mathrm{Na}^{+}$balance will be less than that during post-HDF and the $\mathrm{Na}^{+}$load will increase. However, it is difficult to actually measure the Gibbs-Donnan effect; therefore, this consideration is theoretical.

\section{Low-Temperature Dialysis Effect}

With post-HDF, a low-temperature dialysis effect is considered because the substitution fluid is cooled during circuit inflow. Donauer et al. [3] conducted a crossover comparison of post-online HDF, cold dialysis $\left(35.6^{\circ} \mathrm{C}\right)$, and normal HD. With post-online HDF and low-temperature dialysis, the energy transfer rate decreased. However, systolic blood pressure was maintained.

Kumar et al. [4] compared post-HDF and low-temperature dialysis and reported that there was no difference between sodium loading and the changes in intracellular and external fluid volumes calculated by bioimpedance, thus preventing dialysis hypotension with post-HDF. The 
mechanism was determined to be greater due to the low temperature rather than due to the variations in body fluid Na balance. However, the low-temperature dialysis effect cannot be relied on with pre-diluted HDF.

\section{Small-Molecule Solute Removal Reduction Effect}

Because online HDF uses dialysate as a substitution fluid, the amount of dialysate decreases as the removal of small solute decreases. Decreases in dialysate volume are significant during HDF with a higher convective volume, and classical dialysis disequilibrium syndrome is prevented. However, this effect does not occur with post-diluted HDF with a small substitution volume.

Therefore, if we consider the preventive mechanism of dialysis-related hypotension, then there is no clear explanation of mechanisms. In particular, the differences in effects of post-HDF and pre-HDF are unclear. Recently, Smith et al. [5] conducted a random crossover study of high-flux HD (HFHD) and post-online HDF (convection volume $20 \mathrm{~L}$ ) involving 100 subjects and a blinded method; there was no difference in recovery time after dialysis and significantly more dialysis hypotension reported with HDF. The fact that the superiority of HDF was denied in a strict crossover study such as this is an objection to the prevention of dialysis-related hypotension.

\section{Effects of Improving Survival}

To overcome the limitations of previous observation studies, large RCTs have been conducted in Europe, such as the Dutch CONTRAST [6] (comparison between postonline HDF and low-flux HD), the Turkish Study [7], the ESHOL study [2], and the French study [8] (the latter 3 compared post-online HDF and HFHD).

In the CONTRAST, there was no difference in survival during the overall analysis, but the $38 \%$ risk of death decreased for the group with a convection volume greater than $21.95 \mathrm{~L}$ [6].

In the Turkish study, although there was no significant difference between all-cause mortality, death due to cardiovascular disease (CVD), hospitalization, and dialysisrelated hypotension for both groups, similar to CONTRAST, survival was good for those with a convection volume greater than $17.4 \mathrm{~L}$, and risk reductions of $46 \%$ for all-cause mortality and $71 \%$ for death due to CVD were observed [7].

In the ESHOL study, the primary analysis showed a $30 \%$ decrease in all-cause mortality, a 35\% decrease in

Is There Enough Evidence to Prove That

Hemodiafiltration Is Superior? death due to CVD, and a 55\% decrease in infectious disease - related deaths; the frequency of dialysis hypotension occurrence also decreased by $28 \%$. Similar to these 2 RCTs, total reductions in death of 40 and $45 \%$ were achieved in groups with convection volumes of 23-25 and $>25$ L, respectively [2].

These 3 RCTs showed similar results, indicating that post-HDF and high-convection volume HDF have a good influence on survival rates. However, a high blood flow rate is essential for obtaining a high convection volume with post-online HDF. In other words, it can be inferred that survival rates were good when a high blood flow rate could be obtained.

An investigation involving the results of the French study, previously mentioned RCTs, and convection volumes was reevaluated (pooled individual participant data analysis) [9-11]. It was assumed that the effect on allcause mortality and CVD mortality rates due to the difference in convection volume was found when the convection volume was normalized according to the body surface area. A retrospective, large-scale, comparative observational study (European Clinical Database) showed that by converting the convection volume according to the body surface area, it is possible that higher convection volumes have a clear effect on survival [12]. In this observational study, the increase in convection volume was correlated with the improvements in survival rates and decreased C-reactive protein. Further correlations were also shown between decreased C-reactive protein and improvements in survival rates.

Although the RCTs and observational studies showed that survival rates improve with increased convection volumes with post-HDF, the mechanism is not clear. Compared to HD, removal of large solutes increases with both pre- and post-HDF, and this removal is proportional to the increase in convection volume. That is, an increase in convection volume leads to an increase in the removal of large solutes and a decrease in mortality rates. This hypothesis was devised when dialysis therapy was first introduced. The uremic target substance spread from small molecules to middle molecules with $\beta 2$ microglobulin. However, the significance of the uremic substance with more solute is still not clear, and the target solute has not been determined.

The French study was a comparison of online HDF and HFHD for elderly individuals (older than 65 years). Although the durability of online HDF was confirmed, survival did not differ between the 2 groups [9]. The most recent clinical study involved an analysis of survival with HDF using Euro-DOPPS 4-5 [13]. Unlike the study using 
Euro-DOPPS 1 [14], the superiority of HDF was not shown. The research and analysis styles were the same; therefore, HDF does not yet have established effects on survival rates.

All studies performed in Europe involved post-dilution HDF. In Japan, pre-diluted HDF is used for 95\% of patients. Therefore, the Japanese Renal Data Registry compares the 1-year prognosis of pre-HDF and HD using the propensity score - matched method based on the national database [15]. Pre-HDF with a higher convective volume (>40 L) decreased all-cause mortality and CVD mortality compared with HD or HDF with a small convective volume.

The effectiveness of HDF is still unclear. Therefore, large-scale studies performed in many regions attempting to elucidate the mechanisms of effectiveness are necessary.

\section{Disclosure Statement}

The author declares no competing interests.

\section{References}

1 Locatelli F, Altieri P, Andrulli S, Bolasco P, Sau G, Pedrini LA, Basile C, David S, Feriani M, Montagna G, Di Iorio BR, Memoli B, Cravero R, Battaglia G, Zoccali C: Hemofiltration and hemodiafiltration reduce intradialytic hypotension in ESRD. J Am Soc Nephrol 2010;21:1798-1807.

2 Maduell F, Moreso F, Pons M, Ramos R, Mora-Macià J, Carreras J, Soler J, Torres F, Campistol JM, Martinez-Castelao A: Highefficiency postdilution online hemodiafiltration reduces all-cause mortality in hemodialysis patients. J Am Soc Nephrol 2013;24:487497.

3 Donauer J, Schweiger C, Rumberger B, Krumme B, Böhler J: Reduction of hypotensive side effects during online-haemodiafiltration and low temperature haemodialysis. Nephrol Dial Transplant 2003;18:16161622.

4 Kumar S, Khosravi M, Massart A, Potluri M, Davenport A: Haemodiafiltration results in similar changes in intracellular water and extracellular water compared to cooled haemodialysis. Am J Nephrol 2013;37:320-324.

5 Smith JR, Zimmer N, Bell E, Francq BG, McConnachie A, Mactier R: A randomized, single-blind, crossover trial of recovery time in high-flux hemodialysis and hemodiafiltration. Am J Kidney Dis 2017;69:762-770.

6 Grooteman MP, van den Dorpel MA, Bots ML, Penne EL, van der Weerd NC, Mazairac $\mathrm{AH}$, den Hoedt $\mathrm{CH}$, van der Tweel I, Lévesque R, Nubé MJ, Ter Wee PM, Blankestijn PJ: Effect of online hemodiafiltration on all-cause mortality and cardiovascular outcomes. J Am Soc Nephrol 2012;23:1087-1096.

7 Ok E, Asci G, Toz H, Ok ES, Kircelli F, Yilmaz M, Hur E, Demirci MS, Demirci C, Duman S, Basci A, Adam SM, Isik IO, Zengin M, Suleymanlar G, Yilmaz ME, Ozkahya M: Mortality and cardiovascular events in online haemodiafiltration (OL-HDF) compared with highflux dialysis: results from the Turkish OLHDF study. Nephrol Dial Transplant 2013;28: 192-202.

8 Morena M, Jaussent A, Chalabi L, Leray-Moragues H, Chenine L, Debure A, Thibaudin D, Azzouz L, Patrier L, Maurice F, Nicoud P, Durand C, Seigneuric B, Dupuy AM, Picot MC, Cristol JP, Canaud B: Treatment tolerance and patient-reported outcomes favor online hemodiafiltration compared to high-flux hemodialysis in the elderly. Kidney Int 2017;91: 1495-1509.

9 Davenport A, Peters SA, Bots ML, Canaud B, Grooteman MP, Asci G, Locatelli F, Maduell F, Morena M, Nubé MJ, Ok E, Torres F, Woodward M, Blankestijn PJ; HDF Pooling Project Investigators: Higher convection volume exchange with online hemodiafiltration is associated with survival advantage for dialysis patients: the effect of adjustment for body size. Kidney Int 2016;89:193-199.

10 Peters SA, Bots ML, Canaud B, Davenport A, Grooteman MP, Kircelli F, Locatelli F, Maduell F, Morena M, Nubé MJ, Ok E, Torres F, Woodward M, Blankestijn PJ; HDF Pooling Project Investigators: Haemodiafiltration and mortality in end-stage kidney disease pa- tients: a pooled individual participant data analysis from four randomized controlled trials. Nephrol Dial Transplant 2016;31:978984.

11 Nubé MJ, Peters SAE, Blankestijn PJ, Canaud B, Davenport A, Grooteman MPC, Asci G, Locatelli F, Maduell F, Morena M, Ok E, Torres F, Bots ML; HDF Pooling Project investigators: Mortality reduction by post-dilution online-haemodiafiltration: a cause-specific analysis. Nephrol Dial Transplant 2017;32: 548-555.

12 Canaud B, Barbieri C, Marcelli D, Bellocchio F, Bowry S, Mari F, Amato C, Gatti E: Optimal convection volume for improving patient outcomes in an international incident dialysis cohort treated with online hemodiafiltration. Kidney Int 2015;88:1108-1116.

13 Locatelli F, Karaboyas A, Pisoni RL, Robinson BM, Fort J, Vanholder R, Rayner HC, Kleophas W, Jacobson SH, Combe C, Port FK, Tentori F: Mortality risk in patients on hemodiafiltration versus hemodialysis: a "realworld" comparison from the DOPPS. Nephrol Dial Transplant 2017, Epub ahead of print.

14 Canaud B, Bragg-Gresham JL, Marshall MR, Desmeules S, Gillespie BW, Depner T, Klassen P, Port FK: Mortality risk for patients receiving hemodiafiltration versus hemodialysis: European results from the DOPPS. Kidney Int 2006;69:2087-2093.

15 Masakane I, Kikuchi K, Kawanishi H: Evidence for the clinical advantages of predilution on-line hemodiafiltration. Contrib Nephrol 2017;189:17-23. 